\title{
Diffusion Properties of Carbonated Caprocks from the Paris Basin
}

\author{
P. Berne ${ }^{1 *}$, P. Bachaud ${ }^{1}$ and M. Fleury ${ }^{2}$ \\ 1 CEA, LITEN, L2T, 38054 Grenoble - France \\ 2 Institut français du pétrole, IFP, 1-4 avenue de Bois-Préau, 92852 Rueil-Malmaison Cedex - France \\ e-mail: philippe.berne@cea.fr - pierre.bachaud@cea.fr - marc.fleury@ifp.fr \\ * Corresponding author
}

Résumé - Propriétés diffusives de roches de couverture carbonatées du Bassin de Paris L'efficacité d'un stockage géologique de $\mathrm{CO}_{2}$ repose sur les propriétés de confinement des roches de couverture. Parmi ces propriétés, les caractéristiques diffusives jouent un rôle important qui est parfois sous-estimé. En effet, la diffusion est un processus lent mais qui peut s'avérer non négligeable sur le long terme. De plus, les caractéristiques recherchées pour une roche de couverture, principalement une forte pression d'entrée et une faible perméabilité, ne sont pas incompatibles avec des coefficients de diffusion relativement élevés, puisque ces grandeurs sont liées à des caractéristiques géométriques différentes (schématiquement, les tailles de pore pour les unes et la tortuosité pour les autres). Dans le cadre du projet Géocarbone-INTÉGRITÉ, financé par l'ANR de 2006 à 2008, on a donc mesuré les coefficients de diffusion de l'eau et de l'ion bicarbonate dans des échantillons de roche de couvertures carbonatées provenant de trois niveaux (formations des Calcaires du Comblanchien et de la Dalle Nacrée). Ces deux espèces permettent en effet de couvrir, en première approximation, les situations rencontrées en conditions de stockage (espèce neutre/espèce chargée, interagissant ou non avec la matrice solide). Dans un premier temps, on présente le modèle simple de diffusion utilisé pour le dépouillement des expériences, ce qui permet de passer en revue les différentes grandeurs utiles : coefficient de diffusion effectif, coefficient de diffusion de pore, coefficient de diffusion apparent, porosité accessible, facteur de retard. Le coefficient d'autodiffusion de l'eau est mesuré par deux techniques différentes (Résonance Magnétique Nucléaire et traçage radioactif à l'eau tritiée ${ }^{1} \mathrm{H}^{3} \mathrm{HO}$ ) dans deux échantillons. Les résultats obtenus sont comparables : porosité de l'ordre de $6 \%$, coefficient de diffusion de pore de l'ordre de $2 \times 10^{-10} \mathrm{~m}^{2} / \mathrm{s}$, tortuosité proche de 10 . Le traçage de l'eau tritiée et de l'ion bicarbonate marqué au carbone $14, \mathrm{H}^{14} \mathrm{CO}_{3}^{-}$, est ensuite appliqué aux trois types d'échantillons. Il met en évidence une diminution de la porosité accessible à l'ion bicarbonate, diminution que l'on attribue à l'exclusion anionique. L'interaction entre l'ion bicarbonate et la matrice solide est également visible - ce qui suggère une capacité de stockage du $\mathrm{CO}_{2}$ dans les roches de couverture carbonatées (indépendamment des problèmes de leur altération par l'eau acidifiée, qui n'est pas abordé). Enfin, on propose quelques règles simples de transposition des résultats obtenus à d'autres conditions expérimentales.

\begin{abstract}
Diffusion Properties of Carbonated Caprocks from the Paris Basin - The efficiency of geological storage of $\mathrm{CO}_{2}$ lies in the confinement properties of the caprock. Among these properties, diffusive characteristics play an important, though sometimes underestimated, role. Although diffusion is a slow process, it can play a significant role in the long run. Besides, the desirable properties for a caprock - mainly high entry pressure and low permeability - are by no means contradictory with
\end{abstract}


relatively high diffusion coefficients; the reason is that all these quantities do not depend on the same geometrical properties of the porous matrix (pore size in one case, tortuosity in the other). Within the framework of the Géocarbone-INTÉGRITÉ project, financed by the National Research Agency ANR from 2006 to 2008, the diffusion coefficients for water and bicarbonate ions have been measured in caprock samples from three levels (Comblanchien and Dalle Nacrée formations). These two species cover the main situations encountered in storage site conditions (neutral/charged species, interacting or not with the solid matrix). The model used for interpretation of the experiments is presented; this enables review of various quantities of interest: effective diffusion coefficient, pore diffusion coefficient, apparent diffusion coefficient, retardation factor. The pore self-diffusion coefficient for water was measured by two different techniques (Nuclear Magnetic Resonance and tritiated water ${ }^{1} \mathrm{H}^{3} \mathrm{HO}$ tracing) on two samples. The results are comparable: porosity about $6 \%$, pore diffusion coefficient $2 \times 10^{-10} \mathrm{~m}^{2} / \mathrm{s}$, tortuosity about 10. The radioactive tracer method is then applied with tritiated water and carbon-14-tagged bicarbonate ions, $\mathrm{H}^{14} \mathrm{CO}_{3}^{-}$, to samples from three depth levels. Reduction of accessible porosity is evidenced for bicarbonate ions, which is attributed to anionic exclusion. Interaction between bicarbonate ions and the solid matrix is also shown. This suggests that additional $\mathrm{CO}_{2}$ storage capacity might be offered by carbonated caprocks (regardless of the problem of alteration by acidified water, not addressed here). Lastly, a few simple rules for extending the results presented here to other experimental conditions are proposed.

\section{INTRODUCTION}

Molecular diffusion is a slow transport process at the time scale of injection in a storage site. However, due to the rapid migration of $\mathrm{CO}_{2}$ at the base of the caprock acting as a seal, long term diffusion transport should be evaluated carefully for possible additional storage capacity [1] and for sealing efficiency. Caprocks are characterized by high entry capillary pressure and low permeability. However, diffusion and permeability are distinct mechanisms that do not depend upon the same petrophysical properties. If we take a simple system of packed grains of uniform grain size, permeability typically depends on the square of the grain size whereas porosity and diffusion will be constant in this particular case. Therefore, despite the very low permeability of caprocks, diffusion coefficients can be significant and only reduced by one or two orders of magnitude compared to free water values. In contrast, caprocks may have a significant porosity (e.g. 20\%) but a permeability reduced by six orders of magnitude or more compared to the reservoir zone. This is due to the fact that caprocks are made of fine grains such as clay particles, and/or they have been subjected to specific diagenetic processes such as dissolution/recrystallization.

This paper reports measurements of diffusion coefficients in samples of water-saturated carbonated rocks. The selfdiffusion coefficient of water is a basic characteristic in a saturated rock sample because it involves the main component of the pore solution and can be used as a reference for other substances. It was measured by two methods, a Nuclear Magnetic Resonance (NMR) concentration method and a radioactive tracer method using tritiated water. The results from both are compared and discussed. The self-diffusion coefficient of bicarbonate ions, $\mathrm{H}^{14} \mathrm{CO}_{3}^{-}$, was also measured.
One objective was to look into the influence of the electric charge of the diffusing species; there is abundant literature on the subject concerning argillaceous formations but much less in the case of carbonated rocks. The other objective was to investigate the interaction of dissolved carbonates with the solid matrix of caprock samples that are also mainly composed of carbonates. The radioactive tracer method was applied using sodium bicarbonate tagged with carbon-14. Lastly, an attempt was made at extending the results to other experimental conditions and possibly to other types of rocks.

\section{EFFECTIVE AND PORE DIFFUSION, RETARDATION FACTOR}

The results from the NMR and radioactive tracer experiments are analyzed using a simple model for diffusion in a porous medium. It is useful to describe this model in some detail since the basic notions are not always clearly defined.

Several types of diffusion can be distinguished [2]. Here we shall be mainly concerned with "self-diffusion", i.e. the movement of a species at chemical equilibrium (with no concentration gradient) due to Brownian motion. Isotopic tracers are ideally suited for this kind of measurements since they allow preservation of the chemical nature and composition of the pore solution while detecting the movement of tagged molecules. They are used in all the experiments reported here. The basic approach consists of adding to the solution outside the sample some amount of isotopic tracer and monitoring how it penetrates the sample. In all cases, this results in a concentration versus time curve that has to be interpreted with a diffusion model. 
The idea of diffusion without a chemical gradient may seem contradictory with, for instance, Fick's law, where it is indeed the driving force. This apparent paradox can be reconciled in different manners. Let us first consider self-diffusion in a free solution; let $C$ be the concentration of the chemical form of interest, say the stable bicarbonate ion $\mathrm{H}^{12} \mathrm{CO}_{3}^{-}$, in moles per unit volume of solution; let $c$ be the concentration of the tagged ion, $\mathrm{H}^{14} \mathrm{CO}_{3}^{-}$. The total concentration of bicarbonate ions is $C+c$, where $c$ is negligibly small with respect to $C$ (to give an idea, the mass of tritiated water and $\mathrm{H}^{14} \mathrm{CO}_{3}^{-}$ injected in the radioactive tracer experiments is respectively $5 \times 10^{-8} \mathrm{~g}$ and $4 \times 10^{-5} \mathrm{~g}$ ). The tagged ions should therefore not alter the distribution of $C$, while at the same time creating a minute concentration gradient (because they are added in a part of the experimental setup and not in the other ones). Fick's first law can now be applied to the ion regardless of its isotopic nature:

$$
\vec{J}=-D_{0} \vec{\nabla}(C+c)
$$

where $\vec{J}$ is the flux density of the ion and $D_{0}$ the molecular diffusion coefficient. Since $C$ is uniform (chemical equilibrium), this equation reduces to the following form involving only the concentration of the tracer:

$$
\vec{J}=-D_{0} \vec{\nabla} c
$$

Introducing this equation in a mass balance for the carbonate ion yields:

$$
\frac{\partial(C+c)}{\partial t}=\frac{\partial c}{\partial t}=\nabla \cdot \vec{J}=D_{0} \nabla^{2} c
$$

which is indeed Fick's second law written for the tracer (note that $D_{0}$ is constant because the overall concentration distribution is uniform).

Another possible approach consists in considering the chemical species as a collection of particles undergoing continuous movement under the effect of Brownian agitation that is made visible by the isotopic tracer. Let us now assume for the sake of simplicity that the particles undergo a onedimensional random walk with an equal probability to move by $\pm \Delta z$ at each time interval $\Delta t$. The probability that a particle be at position $z$ at time $t+\Delta t, P(z, t+\Delta t)$, is given by ([3]):

$$
P(z, t+\Delta t)=\frac{1}{2} P(z-\Delta z, t)+\frac{1}{2} P(z+\Delta z, t)
$$

A second order limited development of this equation with vanishingly small $\Delta z$ and $\Delta t$ yields:

$$
\frac{\partial P}{\partial t}=\frac{\Delta z^{2}}{2 \Delta t} \frac{\partial^{2} P}{\partial z^{2}}
$$

which is again Fick's second law of diffusion with $D_{0}=\Delta z^{2} / 2 \Delta t$, considering also that the probability of the presence of a particle is somehow analogous to a concentration. This derivation is very crude and only a simple case is treated here but it can be extended to more complicated and realistic situations. At any rate we consider Equation (2) valid at this stage.
If the solution is contained in the voids of a porous medium, this equation transforms to:

$$
\vec{J}=-D_{e} \cdot \vec{\nabla} c
$$

where $\vec{J}$ now is the flux density of the species of interest per unit surface of porous medium and $c$ the concentration of the tagged isotope per unit volume of pore solution (moles per cubic meter); $D_{e}$ is strictly speaking a diffusion tensor which we shall call the effective diffusion tensor. This law is given here as a "phenomenological" law, but it can be formally derived from diffusion equations at the pore scale under not very stringent assumptions (see for instance [4]). In most of our experiments, diffusion is:

- one-dimensional and;

- perpendicular to rock bedding; Fick's law therefore reduces to a scalar form:

$$
J=-D_{e} \frac{\partial c}{\partial z}
$$

where $D_{e}$ now is the (transverse) effective diffusion coefficient and $z$ the coordinate along the sample axis. If the investigated species does not interact with the solid matrix, which is the case for water for instance, the balance equation reads:

$$
\varepsilon \frac{\partial c}{\partial t}=\frac{\partial}{\partial z}\left(D_{e} \frac{\partial c}{\partial z}\right)
$$

where $\varepsilon$ is the porosity that the species can access. Let us now assume that $D_{e}$ does not depend on position (uniform rock properties). This equation can be rewritten as Fick's second law:

$$
\frac{\partial c}{\partial t}=D_{p} \frac{\partial^{2} c}{\partial z^{2}} \quad D_{p}=D_{e} / \varepsilon
$$

where $D_{p}$ is termed the pore diffusion coefficient. $D_{p}$ is commonly expressed as a function of the molecular diffusion coefficient in a free solution $D_{0}$ as:

$$
D_{p}=\frac{D_{0}}{\tau}
$$

where $\tau$ is the tortuosity. It should be emphasized that $\varepsilon$ and $\tau$ are specific of the porous network that is accessible to the chemical species and may therefore vary according to its electric charge, size, etc.

In the case where the chemical form of interest interacts with the solid matrix, we define $Q$ and $q$ as respectively the concentrations of its usual form and of its isotopic tracer adsorbed on the solid, expressed in moles per unit volume of solid. Equation (8) then reads:

$$
\varepsilon \frac{\partial(C+c)}{\partial t}+(1-\varepsilon) \frac{\partial(Q+q)}{\partial t}=\frac{\partial}{\partial z}\left(D_{e} \frac{\partial(C+c)}{\partial z}\right)
$$

from which $C$ and $Q$ can be eliminated as before because they are uniform and unaffected by the presence of the isotopic tracer:

$$
\varepsilon \frac{\partial c}{\partial t}+(1-\varepsilon) \frac{\partial q}{\partial t}=\frac{\partial}{\partial z}\left(D_{e} \frac{\partial c}{\partial z}\right)
$$


Isotopic exchange takes place between the liquid and solid phases. It is characterized by fractionation factor $\alpha$ :

$$
\alpha=\frac{q / Q}{c / C}
$$

The fractionation factor usually differs from unity by less than a few percents. This difference is of course crucial in several fields of science but for our own practical purpose it can be neglected to yield:

$$
q=\alpha \frac{Q}{C} c \approx \frac{Q}{C} c=K c
$$

where $K=Q / C$ is a constant that plays the role of a partition coefficient for the isotopic tracer; with the units adopted here for $Q$ and $C, K$ is dimensionless. Combining Equations (12) and (14) finally yields:

$$
\frac{\partial c}{\partial t}=D_{a p p} \frac{\partial^{2} c}{\partial z^{2}}
$$

where the apparent diffusion coefficient $D_{a p p}$ is given by:

$$
D_{\text {app }}=\frac{D_{e}}{\varepsilon+(1-\varepsilon) K}=\frac{D_{e}}{R \varepsilon}=\frac{D_{p}}{R}
$$

$R=1+(1-\varepsilon) K / \varepsilon$ (dimensionless) is commonly called the "retardation factor" because a value larger than one results in decreasing the apparent diffusion coefficient and hence slowing down diffusion with respect to a non-interacting species. In other words, the breakthrough time of an interacting species with retardation factor $R$ will be $R$ times larger than the breakthrough time of a non-interacting one. The retardation factor depends on many factors: nature of porous matrix, composition of pore water, concentration and obviously nature of the diffusing species, etc. This subject is quite important for the safety of geological nuclear waste depositories and has been investigated in some detail. To give a few orders of magnitude, typical values for cations might range from less than 10 for $\mathrm{Na}^{+}$(deduced from [5]), to $10^{3}-10^{4}$ for $\mathrm{Cs}^{+}[6]$. The case of anions is more complicated and will be examined in more detail in Section 4.

The terminology adopted here (effective, pore and apparent diffusion coefficient) is unfortunately not universal; to cite two recent papers on parent subjects ([1] and [7]), the latter uses it while the former does not (the so-called "effective diffusion coefficient" in [1] is actually what we denote here the pore diffusion coefficient $D_{p}$ ).

\section{EXPERIMENTAL TECHNIQUES}

We describe here the NMR and radioactive tracer techniques used on several samples from a caprock formation (Charmottes, France).

\subsection{Samples}

The samples come from an oilfield located $100 \mathrm{~km}$ south east of Paris (Charmottes). In the framework of an integrated program (Geocarbon Integrity), petrophysical, petrographical and mineralogical characterizations were performed on several sections of the caprock [8]. They are part of the top of the Dogger formation (Bathonian and Callovian geological units). The samples studied here come from three cores (106, 107 and 109). The 106 and 109 cores are respectively part of the Comblanchien and Dalle Nacrée formations, the 107 core belongs to a transitional unit between these two formations. Table 1 presents their main characteristics.

TABLE 1

Main characteristics of the samples

\begin{tabular}{c|c|c|c}
\hline Sample & 106 & 107 & 109 \\
\hline Facies & $\begin{array}{c}\text { Mudstone to } \\
\text { wackestone-packstone }\end{array}$ & $\begin{array}{c}\text { Wackestone } \\
\text { to packstone }\end{array}$ & $\begin{array}{c}\text { Pre-reef } \\
\text { deposit }\end{array}$ \\
\hline $\begin{array}{c}\text { Mineralogical } \\
\text { composition }\end{array}$ & Calcite 95\% & $\begin{array}{c}\text { Ankerite 30\% } \\
\text { Quartz 20\% } \\
\text { Minor clays } \\
\text { Gypsum }\end{array}$ & $\begin{array}{c}\text { Calcite 90\% } \\
\text { Pyrite 5\% } \\
\text { Gypsum } \\
\text { Quartz }\end{array}$ \\
\hline $\begin{array}{c}\text { Porosity (mercury } \\
\text { intrusion) }(\%)\end{array}$ & $2-3$ & 6 & 6 \\
\hline Permeability $(\mu \mathrm{D})$ & 0.2 & 0.05 & 4 \\
\hline
\end{tabular}

Three cylindrical samples (diameter $49 \mathrm{~mm}$ - thickness $6 \mathrm{~mm}$ ) were taken from core 106 and used for radioactive tracer tests with tritiated water. One of them was also used for a carbon-14 tracer experiment. Four cylindrical $49 \mathrm{~mm}$ by $6 \mathrm{~mm}$ samples were cut from core 107 for the tritiated water experiments, one being also used for a carbon-14 test. Two smaller samples (a cube and a cylinder, both $10 \mathrm{~mm}$ in side/diameter and height), hereafter denoted Charm 107-1 and Charm 107-2, were also cut and used both for the NMR and the radioactive tests with tritiated water. Only one sample ( $40 \mathrm{~mm}$ by $6 \mathrm{~mm}$ cylinder) from core 109 was used for the radioactive tracer tests (tritiated water and carbon-14), because that material was very scarce. In all cases, the samples were not dried but simply resaturated by putting them in brine at high pressure (200 bar) during 1 week in order to eliminate any air inside them.

\subsection{NMR Porosity and Diffusion Measurements}

We used a low field NMR technique to:

- measure precisely the pore volume without drying the sample;

- obtain a pore structure information from the relaxation time distribution;

- measure diffusion coefficients. The NMR spectrometer is a MARAN 23.7 MHz from Oxford Instruments equipped with a $18 \mathrm{~mm}$ diameter probe and up to $300 \mathrm{G} / \mathrm{cm} 1 \mathrm{D}$ vertical pulsed gradients. 
In NMR relaxation experiments, we measure the magnetization decay characterized by the so-called $T_{2}$ relaxation time, resulting essentially from liquid-solid interactions of the spins carried by molecules exploring the pore space by diffusion. The solid-liquid interactions are effective only close to the surface in a layer of thickness $\varepsilon_{s}(<1 \mathrm{~nm})$. The volume fraction of the pore volume is $f_{b}$ (bulk volume), and $f_{s}$ is the volume fraction of the surface layer $\left(f_{b}+f_{s}=1\right)$. As a result of molecular diffusion, there is an exchange between the surface and bulk volumes with a typical exchange time $\tau_{e x}$. In the so-called fast exchange regime $\left(\tau_{e x}<<T_{2}\right)$, the relaxation time $T_{2}$ is an average of the bulk and surface relaxation rates weighted by the volume fraction:

$$
\frac{1}{T_{2}}=\frac{f_{s}}{T_{2 s}}+\frac{f_{B}}{T_{2 B}} \approx \frac{\varepsilon_{s} S_{p}}{V_{p}} \frac{1}{T_{2 s}}+\frac{1}{T_{2 B}}
$$

$T_{2 s}$ is the relaxation time characteristic of the surface layer, $T_{2 B}$ is the relaxation time of the bulk liquid $\left(T_{2 s} \ll T_{2 B}\right)$, and $V_{p}$ and $S_{p}$ are respectively the volume and surface of a pore. An important parameter describing the strength of solid liquid interactions is the surface relaxivity $\rho_{2}$ or relaxation velocity at the pore surface defined as $\rho_{2}=\varepsilon_{s} / T_{2 s}$. The relaxation time $T_{2}$ can then be expressed by:

$$
\frac{1}{T_{2}}=\rho_{2} \frac{S_{p}}{V_{p}}+\frac{1}{T_{2 B}}
$$

The above equation is the basis for the interpretation of relaxation time as an indicator of pore size expressed as the ratio $V_{p} / S_{p}$. Note that this ratio includes a pore shape and a surface rugosity. In the presence of a distribution of pore sizes, or more precisely a distribution of $V_{p} / S_{p}$, the magnetization decay $M(t)$ is no more a single exponential but the sum of the contribution from all pores. $M(t)$ is then analyzed in term of a discrete series of exponential decays such as:

$$
M(t)=\sum_{i} A_{i} \exp \left(-\frac{t}{T_{2 i}}\right)
$$

where $A_{i}$ represents the number of spins associated with a relaxation time $T_{2 \mathrm{i}}$. The plot of a $T_{2}$ distribution consists of a plot of the curve $A\left(T_{2}\right)$ estimated usually at 80 discrete predefined $T_{2 \mathrm{i}}$ values. The total magnetization $M(t=0)$ represents the total amount of detectable spins and is converted to a volume of water by comparison with a water sample of known volume. The relaxation time distributions were calculated using the IFP software MEA (Multi-Exponential-Analysis) not detailed here. The measurements were performed using a standard CPMG sequence with an inter-echo time of $0.06 \mathrm{~ms}$ (an inter-pulse spacing of $0.03 \mathrm{~ms}$ ). Therefore, we consider that the smallest detectable relaxation time is $T_{2}=0.06 \mathrm{~ms}$. The signal to noise ratio is usually greater than 100 .

The $T_{2}$ relaxation time distributions obtained on two companion samples indicate three pore size groups (Fig. 1). If we chose a typical surface relaxivity $\rho_{2}=5 \mu \mathrm{m} / \mathrm{s}$, a relaxation time of $1 \mathrm{~ms}$ corresponds to a $V / S$ ratio of $5 \mathrm{~nm}$. As a
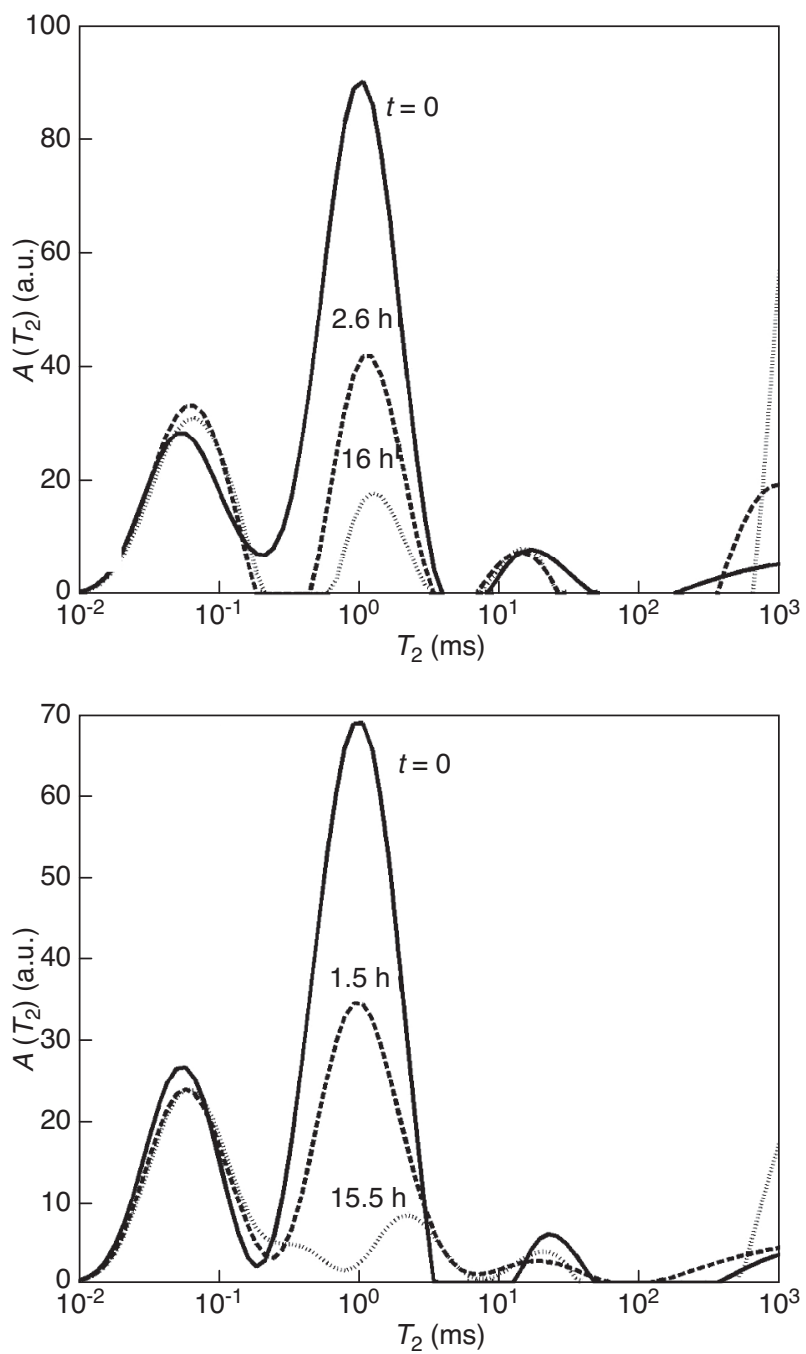

Figure 1

Measurement of $T_{2}$ relaxation time distributions on two samples. Full lines: fully saturated samples before immersion in $\mathrm{D}_{2} \mathrm{O}$. Dashed lines: distribution after immersion in $\mathrm{D}_{2} \mathrm{O}$. Top: sample Charm 107-1; bottom: sample Charm 107-2.

guide only, for a dense sphere pack, the resulting sphere diameter would be about $100 \mathrm{~nm}(V / S=0.058 d)$. At very short time $\left(T_{2}<0.2 \mathrm{~ms}, 15 \%\right.$ of the total proton population), we observed a nanoporosity. For clays, it would correspond to protons located in interlayers. In the present situation, this population should rather be interpreted as water isolated in recrystallized micrite or intra crystalline water. As will be seen later, these protons were not exchanged with $\mathrm{D}_{2} \mathrm{O}$ and the corresponding porosity should be considered as unconnected porosity. The second population is located around $1 \mathrm{~ms}$ and constitutes most of the porosity. Finally, there is a small porosity at $10 \mathrm{~ms}$ ( $3.4 \%$ of the total proton population) which was surprisingly not exchanged with $\mathrm{D}_{2} \mathrm{O}$, although 
this population represents the largest pores in the system. Again, the recrystallisation mechanisms occurring during the formation of the caprock may be at the origin of this isolated porosity. To calculate the effective porosity, we removed the non exchangeable protons from the signal.

Concerning diffusion, our equipment allows the measurement of effective self-diffusion coefficients as detailed in [9]. However, because we follow the magnetization carried by molecules and not directly their displacements, the life time of the magnetization must be long enough. For our system, the pulsed field gradient sequence cannot be used because most of the magnetization has decreased to zero (about $5 T_{2}=$ $5 \mathrm{~ms}$, Fig. 1) before a diffusion echo can be recorded (at about $8 \mathrm{~ms}$ ). Therefore, we chose to use a deuterium tracer technique as explained in Figure 2. The sample initially saturated with a low salinity brine $(5 \mathrm{~g} / \mathrm{L} \mathrm{NaCl})$ is immersed in $\mathrm{D}_{2} \mathrm{O}$ (purity $99.5 \%$ ). Because $\mathrm{D}_{2} \mathrm{O}\left({ }^{2} \mathrm{H}\right)$ has a very different resonance frequency (in our case $3.6 \mathrm{MHz}$ ) and is therefore not measured, we can measure a ${ }^{1} \mathrm{H}$ water concentration
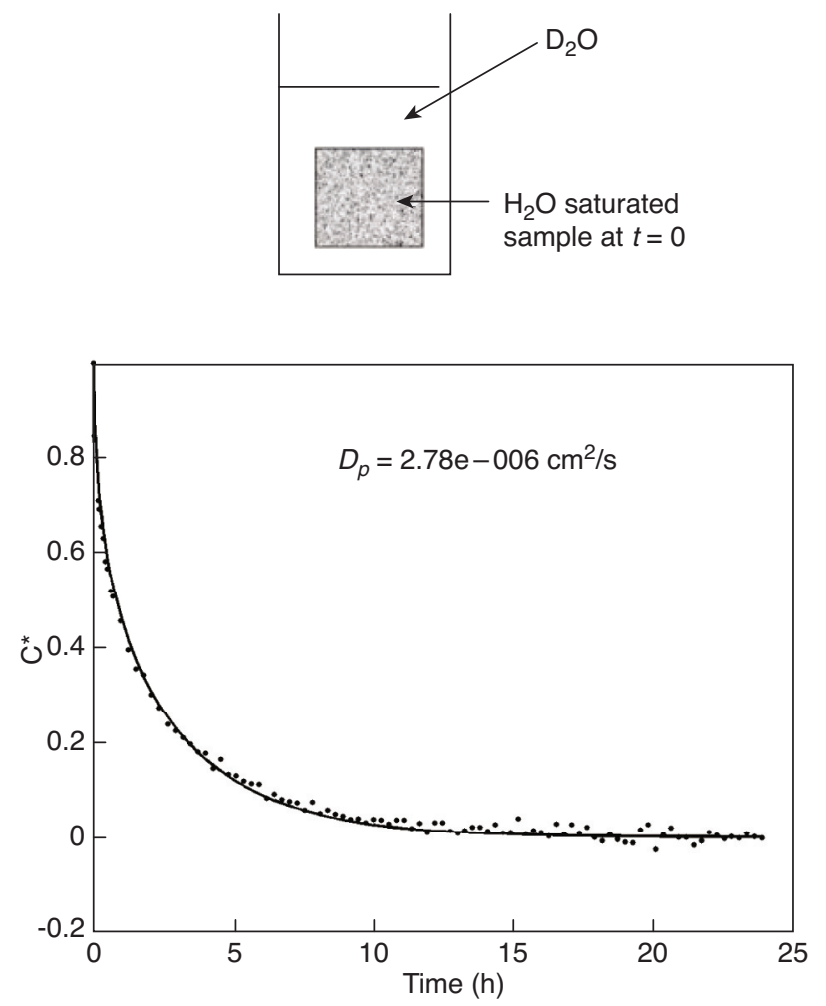

Figure 2

Top: schematic of the experiment for measuring diffusion coefficients using NMR. The sample, initially saturated with $\mathrm{H}_{2} \mathrm{O}$, is immersed in $\mathrm{D}_{2} \mathrm{O}$. The $T_{2}$ distribution is recorded at regular interval to measure the magnetization decay in the sample due to diffusion of $\mathrm{D}_{2} \mathrm{O}$ into the sample. Bottom: average normalized water concentration $(E q .20)$ as a function of time $(\bullet)$ and data fitting using $D_{p}=2.78 \times 10^{-6}$ $\mathrm{cm}^{2} / \mathrm{s}$ and $l=0.5 \mathrm{~cm}(-)$. The temperature was $T=30^{\circ} \mathrm{C}$. decreasing as a function of time by simply recording the magnetization as a function of time (Fig. 2). This simple technique has the great advantage of revealing also the non accessible porosity, as described above.

Without the need for calibration, the magnetization can be expressed in terms of ${ }^{1} \mathrm{H}$ concentration $\mathrm{C}$. The following equations applicable to a cylinder or a cube were used to analyze the data [11]:

$$
\begin{array}{cc}
C^{*}=\frac{C-C_{f}}{C_{i}-C_{f}}=C_{p s}^{3} & \text { cube } \\
C^{*}=C_{p s} C_{c y l} \quad \text { cylinder }
\end{array}
$$

where $C_{p s}$ and $C_{c y l}$ are respectively the solution for a plane sheet and an infinite cylinder:

$$
\begin{aligned}
C_{p s} & =\sum_{n=1}^{\infty} \frac{2 \alpha(1+\alpha)}{1+\alpha+\alpha^{2} q_{n^{2}}^{2}} \exp \left(-D_{p} q_{n}^{2} \frac{t}{l^{2}}\right) \\
C_{c y l} & =\sum_{n=1}^{\infty} \frac{4 \alpha(1+\alpha)}{4+4 \alpha+\alpha^{2} q_{n^{2}}^{2}} \exp \left(-D_{p} q_{n}^{2} \frac{t}{r^{2}}\right)
\end{aligned}
$$

and $q_{n}$ are the non-zero positive roots of $\tan q_{n}=-\alpha q_{n}$ in the plane sheet case, and the solution of $\alpha q_{n} J_{0}\left(q_{n}\right)+2 J_{1}\left(q_{n}\right)=0$ in the cylinder case, $J_{\mathrm{i}}$ is the Bessel function of the first kind of order $i, r$ is the radius of the cylinder, $2 l$ the width of the sheet, and $\alpha$ is the volume ratio of deuterium to water ( $\alpha=10$ in our situation and in the cylinder case $r=l$ ). Here, the initial concentration $C_{i}=1$, and the final concentration $C_{f}$ is close to $0 \%$ in the connected porosity. Fitting the data with the above equation gives good results (Fig. 2, a similar fit was obtained for the second sample).

\subsection{Radioactive Tracer Technique}

Radioactive tracer measurements were made using tritiated water (HTO - T stands for tritium, ${ }^{3} \mathrm{H}$ ) and carbon-14 tagged sodium bicarbonate $\left(\mathrm{NaH}^{14} \mathrm{CO}_{3}\right)$ as tracers in a throughdiffusion experimental setup. Through-diffusion [2] basically consists in placing the water-saturated sample between two reservoirs also filled with water (Fig. 3). One of the reservoirs ("upstream" reservoir) is spiked with the tracer, the concentration of which is monitored in the other one as a function of time. Since no pressure gradient is applied, diffusion is the sole mechanism for tracer transport.

The samples are described above. Two of them were previously used in the NMR experiments. All were saturated with salt water with a composition similar to the pore water, hereafter denoted "equilibrated" water. Its compostion is given in Table 2.

Each sample was glued to a polypropylene sample holder using Sikadur epoxy resin. The lateral faces of the samples were completely embedded in the resin, so as to impose a purely one-dimensional configuration. The external faces were parallel to rock bedding (diffusion was therefore 


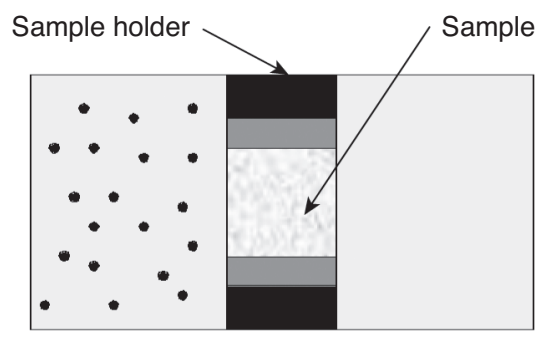

Upstream reservoir: water + tracer

Downstream reservoir: water

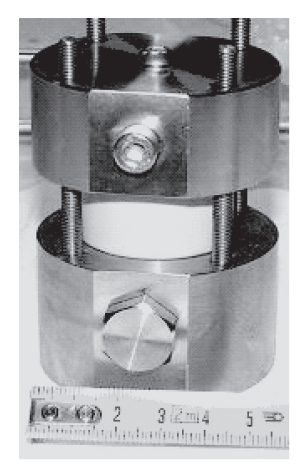

Upstream reservoir

Sample holder

Downstream reservoir

Figure 3

Top: typical setup for a through-diffusion experiment. Bottom: photograph of a diffusion cell.

TABLE 2

Composition of equilibrated water

\begin{tabular}{c|c}
\hline $\mathrm{KCl}$ & $0.0673 \mathrm{~g} / \mathrm{L}$ \\
\hline $\mathrm{MgCl}_{2}-6 \mathrm{H}_{2} \mathrm{O}$ & $0.4676 \mathrm{~g} / \mathrm{L}$ \\
\hline $\mathrm{CaCl}_{2}-2 \mathrm{H}_{2} \mathrm{O}$ & $0.2348 \mathrm{~g} / \mathrm{L}$ \\
\hline $\mathrm{Na}_{2} \mathrm{SO}_{4}$ & $0.9373 \mathrm{~g} / \mathrm{L}$ \\
\hline $\mathrm{NaHCO}_{3}$ & $0.1867 \mathrm{~g} / \mathrm{L}$ \\
\hline $\mathrm{NaCl}$ & $3.6577 \mathrm{~g} / \mathrm{L}$ \\
\hline $\mathrm{Crushed} \mathrm{rock}$ & $1 \mathrm{~g} / \mathrm{L}$ \\
\hline $\mathrm{pH}$ & Approx. 8 \\
\hline
\end{tabular}

perpendicular to the rock strata). The sample holders were then placed in diffusion cells (see an example in Fig. 3). The upstream and downstream reservoirs were also filled with equilibrated water. The diffusion cells were kept at room temperature $\left(23 \pm 1^{\circ} \mathrm{C}\right)$ and atmospheric pressure. An activity of $3 \mathrm{MBq} \mathrm{HTO}$ or $1.5 \mathrm{MBq} \mathrm{NaH}{ }^{14} \mathrm{CO}_{3}$ was added into the upstream reservoir. Samples were taken every day at first; the sampling period was then gradually increased to 4 days. The downstream reservoir was emptied completely at each sampling period, from which a $10 \mathrm{~cm}^{3}$ sample was taken. The downstream reservoir was then refilled with untagged equilibrated water. Sample volume was $0.1 \mathrm{~cm}^{3}$ in the upstream reservoir, complemented with $9.9 \mathrm{~cm}^{3}$ of equilibrated water, so as to have approximately the same activity in the upstream and downstream samples. This procedure allowed maintaining and controlling stable boundary conditions (respectively constant and null volume activity in the upstream and downstream reservoirs).

An equal volume of scintillating cocktail (Instagel Plus) was added in each water sample. The mixture was let to rest for at least six hours. Beta activity was counted twice in each sample using a Packard Tri-carb 2900TR liquid scintillation counter. Typical counting time was 60 minutes. Typical count rates were in the $10^{5}-10^{6} \mathrm{dpm}$ (disintegrations per minute) range. Background level was about 20-25 dpm.

The experiment supplied values for the activity contained in the downstream chamber at each sampling time. They were converted into the time-average of the activity flux density between two samplings, $\bar{J}_{i}$ (average flux density between samples $i-1$ and $i$ ), thanks to a simple activity balance.

Combining Equation (15) with the initial (null activity) and boundary conditions (respectively constant volume activity $a_{0}$ and null volume activity in the upstream and downstream chambers) of the radioactive tracer experiments yields an expression for the instantaneous activity flux density $J$ [11]:

$$
J(t)=a_{0} \frac{D_{e}}{e}\left[1+2 \sum_{n=1}^{\infty}(-1)^{n} \exp \left(-\frac{D_{e} n^{2} \pi^{2}}{R \varepsilon e^{2}} t\right)\right]
$$

where $e$ is the thickness of the sample. Equation (21) shows that $D_{e}$ controls the steady-state flux while the transient part of the experiment is ruled by $D_{a p p}=D_{e} / R \varepsilon$. Values for $D_{e}$ and $R \varepsilon$ were obtained by non-linear fitting of a time-averaged version of Equation (21) against the $\bar{J}_{i}$ values.

Uncertainty on activity measurements was estimated less than $15 \%$. To estimate how it impacts the fitted values for $D_{e}$ and $R \varepsilon$, a collection of 100 datasets were generated from the actual $\bar{J}_{i}$ values of each experiment by adding random Gaussian noise with a $7.5 \%$ standard deviation. Non-linear fitting was then performed and provided a set of $D_{e}$ and $R \varepsilon$ values, the mean of which was taken as the most likely value. Uncertainty was estimated as twice the standard deviation. Uncertainty on $D_{e}$ was usually found less than $10 \%$. Uncertainty on $R \varepsilon$ was much higher and generally larger than $25 \%$, the reason being that the transient part of the experiment was often not well captured. Figure 4 shows a typical result.

\section{RESULTS}

\subsection{Diffusion of Water}

\subsubsection{NMR and Radioactive Tracer Experiments}

The main results obtained with the Charm 107-1/Charm 107-2 samples by NMR and radioactive tracing are gathered in Table 3. 


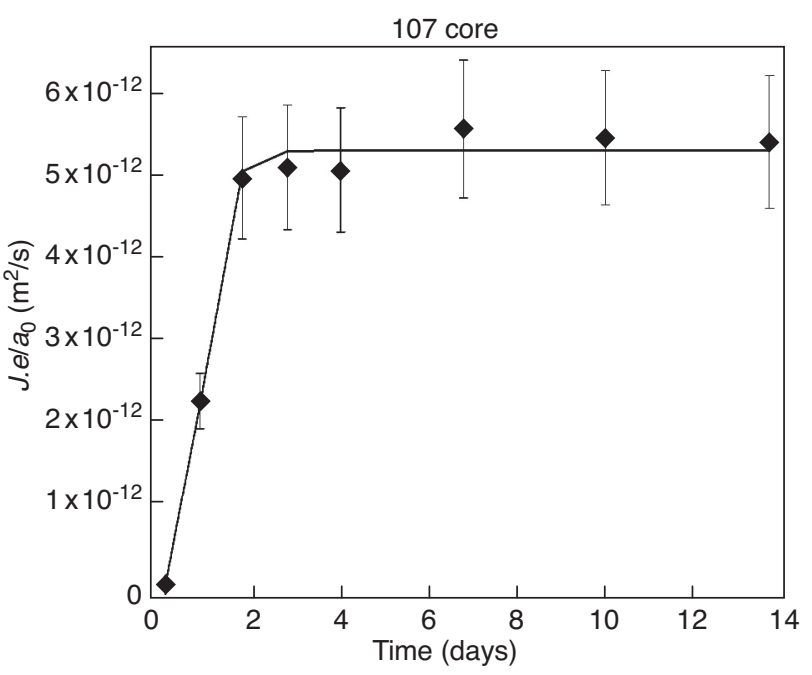

Figure 4

Typical result from a radioactive tracer experiment. The ordinate was chosen as $J . e / a_{0}$ so that the steady-state value is equal to $D_{e}$ (see Eq. 21).

TABLE 3

Results from NMR and Radioactive Tracer (RT) tests

\begin{tabular}{c|c|c}
\hline Sample ID & Charm 107-1 & Charm 107-2 \\
\hline Shape $/$ Size & $\begin{array}{c}\text { Cube } \\
(1.03 \times 1.04 \times 1.09 \mathrm{~cm})\end{array}$ & $\begin{array}{c}\text { Cylinder } \\
(L=D=1.05 \mathrm{~cm})\end{array}$ \\
\hline NMR $\varepsilon(\%)$ & 6.4 & 6.4 \\
NMR $D_{p}\left(\mathrm{~m}^{2} / \mathrm{s}\right)$ & $2.78 \times 10^{-10}$ & $2.51 \times 10^{-10}$ \\
\hline RT $D_{e}\left(\mathrm{~m}^{2} / \mathrm{s}\right)$ & $8 \times 10^{-12}$ & $9.8 \times 10^{-12}$ \\
$\operatorname{RT} \varepsilon(\%)$ & 6 & 7 \\
RT $D_{p}\left(\mathrm{~m}^{2} / \mathrm{s}\right)$ & $1.3 \times 10^{-10}$ & $1.4 \times 10^{-10}$ \\
\hline
\end{tabular}

The NMR experiment is based on a transient diffusion experiment and directly yields a value for the pore diffusion coefficient $D_{p}$. Porosity $\varepsilon$ is deduced from the $M(t)$ distribution as described in the previous section.

The radiotracer experiment basically yields the effective diffusion coefficient $D_{e}$ and the product of the porosity and the retardation factor, $R \varepsilon$. In Table 3 the classical assumption has been made that the retardation factor for water is equal to 1 (no interaction with the solid matrix), hence the value for $\varepsilon$. The pore diffusion coefficient $D_{p}$ is finally calculated as the ratio of $D_{e}$ and $\varepsilon$.

The main observation is that NMR and RT give similar orders of magnitude for $D_{p}\left(10^{-10} \mathrm{~m}^{2} / \mathrm{s}\right)$ and $\varepsilon$ (6 to $\left.7 \%\right)$. Detailed comparison will be made in the "discussion" section.

\subsubsection{Results of the HTO Tracer Experiments}

The whole set of $D_{e}$ values from the HTO tracer experiments is presented in Figure 5. In some cases it has not been possible to evaluate $R \varepsilon$ with any precision because the transient part of the $J(t)$ curve was missed. The HTO porosities are therefore not reported.

These results will also be commented at greater length later. It is sufficient to note for the time being that:

- the order of magnitude of $D_{e}$ is $10^{-11} \mathrm{~m}^{2} / \mathrm{s}$;

- this order of magnitude holds for both 106/107 and 109 samples, even though their permeabilities differ by two orders of magnitude ( $50 \mathrm{nD}$ versus $4 \mu \mathrm{D}$, cf. Tab. 1$)$ - which is a striking confirmation of the different dependences of permeability and diffusion stated in the introduction;

- a variation by a factor of two can be observed between two samples taken $10 \mathrm{~mm}$ apart in the same core, which is significant since uncertainty on $D_{e}$ is about $10 \%$.

\subsection{Self-Diffusion of Bicarbonate lons}

These tests were performed using sodium bicarbonate $\mathrm{NaH}^{14} \mathrm{CO}_{3}$; injecting bicarbonate does not automatically mean that the traced compound is indeed the bicarbonate ion since carbonates exist under three different forms in aqueous solutions: dissolved $\mathrm{CO}_{2}, \mathrm{HCO}_{3}^{-}$and $\mathrm{CO}_{3}^{2-}$. At the $\mathrm{pH}$ of equilibrated water (about 8 ), bicarbonate ions are known to be predominant [12].

The diffusion of charged species is not, as a general rule, correctly described by the Fickian approach adopted here. It should however be noted that the radioactive tracer is introduced in such small quantities that the ionic composition of water is not altered. This means that we are actually monitoring the counterdiffusion of $\mathrm{H}^{12} \mathrm{CO}_{3}^{-}$and $\mathrm{H}^{14} \mathrm{CO}_{3}^{-}$without the other ions being involved, or, in other words, that coupled multicomponent diffusion need not be taken into account and that Fick's laws hold.

Raw results are given in Table 4, expressed in terms of effective diffusion coefficient $D_{e}$ and product $R \varepsilon$. They are commented in the next section.

TABLE 4

Results from carbon-14 tracer tests

\begin{tabular}{c|c|c|c}
\hline Sample & 106 & 107 & 109 \\
\hline$D_{e}\left(\mathrm{~m}^{2} / \mathrm{s}\right) \quad \mathrm{HCO}_{3}^{-}$ & $1.8 \times 10^{-12}$ & $1.3 \times 10^{-12}$ & $10^{-11}$ \\
\hline $\mathrm{R} \varepsilon(\%)$ & 10 & 40 & 450 \\
\hline
\end{tabular}

\section{DISCUSSION AND CONCLUSION}

\subsection{Diffusion of Water}

\subsubsection{Comparison of NMR and Radioactive Tracer Experiments}

Comparison of the NMR and RT results in Table 3 shows that the order of magnitude of $D_{p}$ is indeed the same but that 
the NMR values are larger than the tracer ones, by a factor of approximately two. Several reasons may account for this discrepancy:

- the NMR experiment involves diffusion from/to all the faces of the sample, hence both perpendicular and parallel to the rock strata. On the contrary, the diffusion of radioactive tracer is limited to the perpendicular direction. It is therefore not surprising that the latter should be slower. Values of 2 to 3 for the ratio of parallel to perpendicular diffusion are actually reported in the literature (see for instance [13] for the diffusion of HTO in clay rocks);

- temperatures are different in both experiments (respectively 30 and $23^{\circ} \mathrm{C}$ ). Using the temperature dependence of $D_{0}$, this effect should account for a difference of about $18 \%$ [14];

- measured quantities are not quite the same: the mutual diffusion coefficient for light and heavy water in one case; the tracer diffusion coefficient of tritiated water in light water in the other one. This effect should however be quite minor, since the diffusion coefficients of heavy and tritiated water all lie within less than $10 \%$ of the value for light water as shown by Table 5 [15].

\section{TABLE 5}

Diffusion coefficients for light, heavy and tritiated water at $25^{\circ} \mathrm{C}$

\begin{tabular}{l|l}
\hline Self-diffusion coefficient for $\mathrm{H}_{2} \mathrm{O}$ & $2.27 \times 10^{-9} \mathrm{~m}^{2} / \mathrm{s}$ \\
\hline Tracer diffusion coefficient for $\mathrm{D}_{2} \mathrm{O}$ in $\mathrm{H}_{2} \mathrm{O}$ & $2.11 \times 10^{-9} \mathrm{~m}^{2} / \mathrm{s}$ \\
\hline Tracer diffusion coefficient for $\mathrm{HTO}$ in $\mathrm{H}_{2} \mathrm{O}$ & $2.44 \times 10^{-9} \mathrm{~m}^{2} / \mathrm{s}$ \\
\hline
\end{tabular}

Finally, the porosities deduced from the tracer technique are similar to the NMR values, which are very accurate. However, considering the low precision of the value from the tracer experiment, this observation may be purely circumstantial. The order of magnitude is however confirmed by mercury porosity measurements $(6 \%)$. Temperature- and porosity-corrected values of the pore diffusion coefficient are presented in Table 6.

\section{TABLE 6}

Comparison of NMR and tracer pore diffusion coefficients on two caprock samples at $30^{\circ} \mathrm{C}$. The tracer results from Table 3 have been corrected for temperature and the NMR porosities have been used to calculate the pore diffusion coefficients

\begin{tabular}{l|c|c}
\hline Sample ID & Charm 107-1 & Charm 107-2 \\
\hline Porosity $(\%)$ & 6.4 & 6.4 \\
\hline NMR $D_{p}\left(\mathrm{~m}^{2} / \mathrm{s}\right)$ & $2.8 \times 10^{-10}$ & $2.5 \times 10^{-10}$ \\
\hline RT $D_{p(c o r r)}\left(\mathrm{m}^{2} / \mathrm{s}\right)$ & $1.5 \times 10^{-10}$ & $1.8 \times 10^{-10}$ \\
\hline
\end{tabular}

The value of $D_{0}$ for water is $2.6 \times 10^{-9} \mathrm{~m}^{2} / \mathrm{s}$ at $30^{\circ} \mathrm{C}$ [14]. Equation (10) indicates that the tortuosity of the Charm 107 samples is therefore approximately 10 .

\subsubsection{Results of the HTO Tracer Experiments}

$D_{p}$ values have been deduced from the results in Figure 5 using the porosities from mercury intrusion tests (since NMR porosities are not measured for samples 106 and 109 and RT porosities are not all available). They are presented in Figure 6.

The order of magnitude of $D_{p}$ is again found to be $10^{-10} \mathrm{~m}^{2} / \mathrm{s}$, that is to say about ten times less than $D_{0}$. Tortuosities calculated using (10) are presented in Table 7. The order of magnitude is again 10 , with the same dispersion as found in $D_{e}$ values.

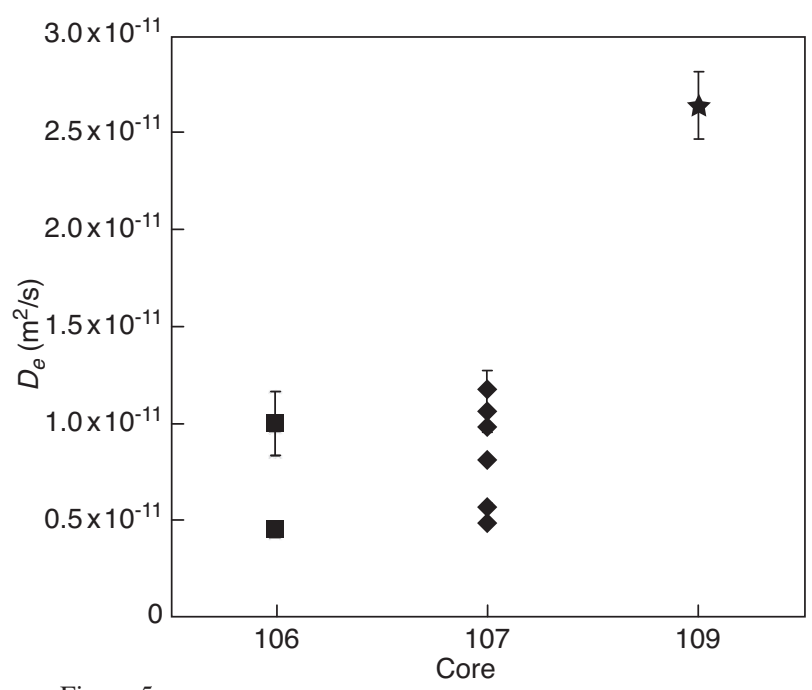

Figure 5

Effective diffusion coefficients obtained with tritiated water.

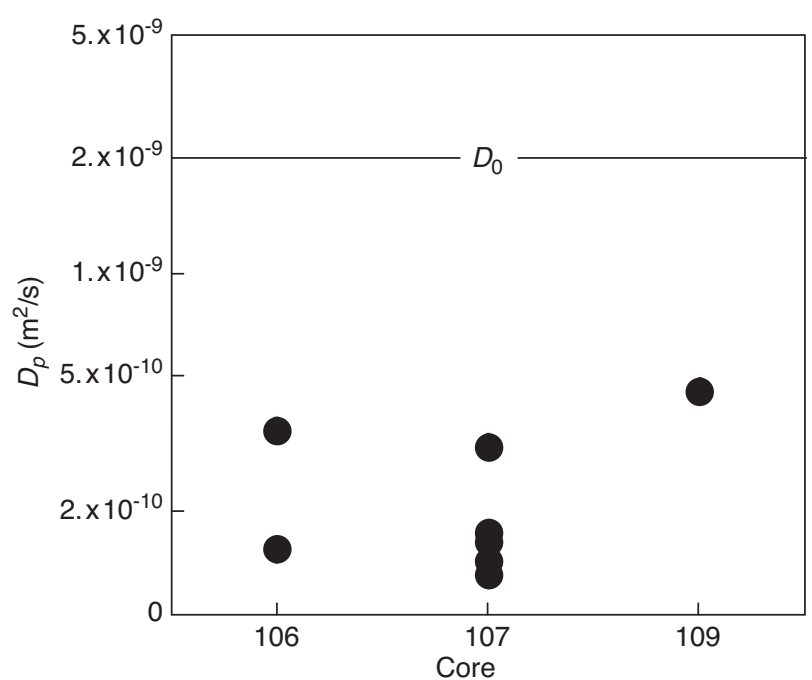

Figure 6

Pore diffusion coefficients obtained with $D_{e}$ from radioactive tracers tests and $\varepsilon$ from mercury intrusion tests - Log scale. The line on top shows the value of $D_{0}$ for tritiated water at $25^{\circ} \mathrm{C}$. 
TABLE 7

Range of tortuosities for each core

\begin{tabular}{l|c|c|c}
\hline Sample & 106 & 107 & 109 \\
\hline Tortuosity $\tau(-)$ & $7-16$ & $8-19$ & 5 \\
\hline
\end{tabular}

\subsection{Comparison of Water and the Bicarbonate Ion}

Combining Equations (9) and (10) yields:

$$
D_{e}=\varepsilon \frac{D_{0}}{\tau}
$$

It was emphasized before that porosity $\varepsilon$ and tortuosity $\tau$ depended closely on the pore network that is accessible to the studied species. If two species can access the same network, Equation (22) predicts the following relationship:

$$
\frac{D_{e}^{1}}{D_{e}^{2}}=\frac{D_{0}^{1}}{D_{0}^{2}}
$$

In the case of water and bicarbonate ions, the $D_{0}$ ratio is approximately 2 [7]. Table 8 shows the $D_{e}^{\mathrm{HTO}} / D_{e}^{\mathrm{HCO}_{3}^{-}}$ratio for each sample.

\section{TABLE 8}

Ratio of effective diffusion coefficients for tritiated water and the bicarbonate ion

\begin{tabular}{l|l|l|l}
\hline Sample & 106 & 107 & 109 \\
\hline$D_{e}^{\mathrm{HTO}} / D_{e}^{\mathrm{HCO}_{3}^{-}}$ & 5.6 & 9.2 & 2.7 \\
\hline
\end{tabular}

The $D_{e}$ ratio is close to the $D_{0}$ ratio in the case of the 109 sample (2.7 instead of 2). As a first approximation, we can consider that in this specific case both species diffuse in the same porous network.

This ratio is significantly larger in the other samples, which means that some phenomenon reduces the porosity or increases the tortuosity for bicarbonate ions (see Eq. 22 - as a matter of fact, a reduction in porosity can be expected to produce an increase in tortuosity, as predicted for instance by Archie's law, see next section). A very likely possibility is anion exclusion: negative charges would concentrate at the surface of the solid matrix and repulse the anionic species that would therefore be excluded from the smaller pores. This phenomenon is well documented in clay rocks (see [7] again). The case of carbonated rocks may be different [16], even though literature does mention measurement of negative charges at the surface of natural calcite $([17,18])$. At any rate, Zeta potential measurements were made on the present samples and actually showed small but significant negative values [19]. The fact that sample 109 behaves differently remains to be explained. One possible reason is that it has a much higher proportion of large diameter pores, as revealed by NMR tests (cf. [8]), which may be a reason why anion exclusion would be minimal.
Another interesting point is the value of the $R \varepsilon$ factor for the bicarbonate ion that is significantly larger than the NMR or mercury porosity. Analysis of the $D_{e}^{\mathrm{HTO}} / D_{e}^{\mathrm{HCO}_{3}^{-}}$ratio has shown that accessible porosity was generally smaller for $\mathrm{HCO}_{3}^{-}$than $\mathrm{HTO}$ but it was not possible to evaluate the former with the available data. It is therefore not possible to calculate the retardation factor $R$ precisely, but a lower limit can be obtained by using the NMR or mercury porosity. The result is given in Table 9.

TABLE 9

Estimate of the retardation factor for the bicarbonate ion

\begin{tabular}{l|c|c|c}
\hline Sample & 106 & 107 & 109 \\
\hline$R \varepsilon(\%)$ & 10 & 40 & 450 \\
\hline$R \varepsilon / \varepsilon_{\text {mercury }}(-)$ & 3.4 & 5.4 & 45 \\
\hline
\end{tabular}

In all cases the retardation factor is found significantly larger than 1. As mentioned in Section 1, it is a sign that some interaction takes place between bicarbonate ions and the solid matrix. This ion is part of the dissolution products of calcite. It is therefore involved in the continuous dissolution/precipitation exchange that occurs between the solid and the liquid phase. Some interaction is therefore to be expected. This mechanism might appear contradictory with the very principle of anionic exclusion: one should in fact note that the largest retardation factor (about 45) is measured in sample 109, in which anion exclusion is very low. Conversely, it is much smaller in the other samples, where anion exclusion is more obvious. The present analysis is therefore consistent even if it cannot be formally proved at this stage.

The fact that the bicarbonate ions interact with the solid matrix of carbonated caprocks suggests that the latter might offer additional storage capacity beyond that of the reservoir formation they cover. Whether it makes them preferable for a $\mathrm{CO}_{2}$ storage site remains questionable, since alteration by $\mathrm{CO}_{2}$-acidified water is also likely to occur.

\subsection{Extension to Other Conditions}

The results presented here provide useful data for modeling diffusion from a potential $\mathrm{CO}_{2}$ storage site. They have been obtained in ambient room conditions, which may strongly differ from site conditions. In this section we suggest several ways to extend the results presented here to other temperature or pressure conditions and porous media of different porosity.

\subsubsection{Temperature Dependence}

Diffusion processes are known to strongly depend on temperature. A $2000 \mathrm{~m}$-deep storage is expected to reach temperatures up to 80 to $100^{\circ} \mathrm{C}$. Because time consuming diffusion experiments are usually performed at a single temperature, we 
suggest taking advantage of Equations (22) and (23) and using the temperature dependence of diffusion in bulk water. Temperature dependences are usually described using Arrhenius laws (see for instance the recent paper [20]). However, in the particular case of self-diffusion of bulk water, this is not exactly true in a wide range of temperature and a more recent and accurate relationship is given by [14]:

$$
\begin{gathered}
D=D_{0}\left[\frac{T}{T_{S}}-1\right]^{\gamma} D_{0}=1.635 \times 10^{-8} \mathrm{~m}^{2} / \mathrm{s}, \\
T_{S}=215.05 \mathrm{~K}, \gamma=2.063
\end{gathered}
$$

The above relation reproduces experimental data within an accuracy better than $1 \%$ in the temperature range [283-373 K]. For example, the water diffusivity is $2.6 \times 10^{-9} \mathrm{~m}^{2} / \mathrm{s}$ at $30^{\circ} \mathrm{C}$ and increases by a factor of 3.3 when the temperature increases up to $100^{\circ} \mathrm{C}$.

\subsubsection{Diffusion of Dissolved $\mathrm{CO}_{2}$}

When $\mathrm{CO}_{2}$ dissolves into water at elevated pressure in an aquifer storage site, acidic $\mathrm{pH}$ conditions will prevail. Under these conditions, aqueous $\mathrm{CO}_{2}$ is the dominant species whereas a small amount is dissociated to form carbonic acid [12]. The experiments reported here have been made with equilibrated water at a $\mathrm{pH}$ of about 8 and are therefore not representative in this respect (though, to be more precise, acidic $\mathrm{pH}$ conditions will be established in the reservoir layer and will then diffuse into the caprock). However, because $\mathrm{CO}_{2}$ has no electrical dipole, it can be considered as neutral with respect to the solid surfaces, hence unaffected by anion exclusion and able to access the same porous network as water. Since the diffusion of $\mathrm{CO}_{2}$ in bulk water $\left(2 \times 10^{-9} \mathrm{~m}^{2} / \mathrm{s}\right.$ at $25^{\circ} \mathrm{C}$, [21]) is lower than but close to the self-diffusion of water $\left(2.27 \times 10^{-9} \mathrm{~m}^{2} / \mathrm{s}\right.$ at the same temperature, see $\left.T a b .5\right)$, the effective self-diffusion coefficient for water can be used as an upper limit for the $D_{e}$ for dissolved $\mathrm{CO}_{2}$. Dissolved $\mathrm{CO}_{2}$ can also be expected to interact with the solid matrix as was observed with bicarbonate ions; whether the retardation factor of bicarbonate ions can be used for dissolved $\mathrm{CO}_{2}$ is nevertheless dubious.

\subsubsection{Resistivity/Diffusion Analogy - Porosity Dependence}

The knowledge about electrical properties can be used to infer diffusion properties in porous media. The well known diffusion-resistivity equivalence is based on the similarity between the governing equations for resistivity and diffusion:

$$
\begin{aligned}
& \left\{\begin{array} { l } 
{ \vec { J } _ { E } = - \frac { 1 } { \sigma } \vec { \nabla } V } \\
{ \frac { \partial V } { \partial t } = - \operatorname { d i v } \vec { J } }
\end{array} \quad \left\{\begin{array}{l}
\vec{J}_{D}=-D \vec{\nabla} C \\
\frac{\partial C}{\partial t}=-\operatorname{div} \vec{J}_{D}
\end{array}\right.\right. \\
& \Rightarrow \frac{\sigma}{\sigma_{0}}=\frac{1}{\varepsilon}\left(\frac{D_{0}}{D_{p}}\right)
\end{aligned}
$$

where $J_{E}$ and $J_{D}$ are the electrical and diffusive flux densities respectively, $V$ is a potential and $C$ is a concentration, $\sigma_{0}$ and $D_{0}$ are the bulk resistivity and diffusivity respectively. The analogy is valid for specific boundary conditions, i.e. the porous media is non conductive, there are no interactions between the diffusive species and the solid. Typically, it will not be valid for the description of the diffusion of ions with charged solid surfaces.

Resistivity is usually modeled as a power law known as the Archie law:

$$
\frac{\sigma}{\sigma_{0}}=\varepsilon^{-m} \Rightarrow \frac{D_{p}}{D_{0}}=\varepsilon^{m-1}
$$

Therefore, after including a porosity normalization, the pore diffusion also depends on porosity but with a smaller exponent. The determination of the $\mathrm{m}$ exponent has been a large area of research and it is well known that $\mathrm{m}$ is not independent of the structure of the porous media. However, a central value of $m=2$ is considered as appropriate when no measurement is available. For bead packs or unconsolidated media, $m$ decreases down to 1.5 , whereas for well cemented systems, it can increase up to 2.5 (a compilation of value for carbonates can be found in [22]). From the present measurements (Tab. 3), we find $1.87<m<2.06$ considering the lowest and highest values.

\subsection{Spatial Extent of the Diffusive Front in the Caprock}

A simple evaluation of the extent of the diffusive front can be made using the following analytical formula:

$$
C(z, t)=\operatorname{erfc}\left(\frac{z}{\sqrt{2 D_{p} t}}\right)
$$

considering a vertical (1D) upward migration of $\mathrm{CO}_{2}$ from the base of the caprock $(z=0)$. To be more realistic, we will assume a temperature of $80^{\circ} \mathrm{C}$ and two porosity values: 5 and $15 \%$. From Equations (24) and (26) $(m=2)$, we obtain $D_{p}=$ $0.33 \times 10^{-9} \mathrm{~m}^{2} / \mathrm{s}$ and $0.99 \times 10^{-9} \mathrm{~m}^{2} / \mathrm{s}$ respectively for $\varepsilon=5$ and $15 \%$. Again, these diffusion coefficients should be viewed as the highest possible values. We see (Fig. 7) that $\mathrm{CO}_{2}$ migration is limited within 10 to $15 \mathrm{~m}$ of caprock after 500 years of diffusion. As expected, diffusion is a very slow transport process.

\section{CONCLUSIONS}

The effective diffusion coefficients for water and for bicarbonate ions were measured in three types of carbonated caprocks from the Paris Basin, under ambient room conditions. In the case of water, two different experimental methods (NMR and the radioactive tracing technique) were applied consecutively to two samples; they yielded consistent 


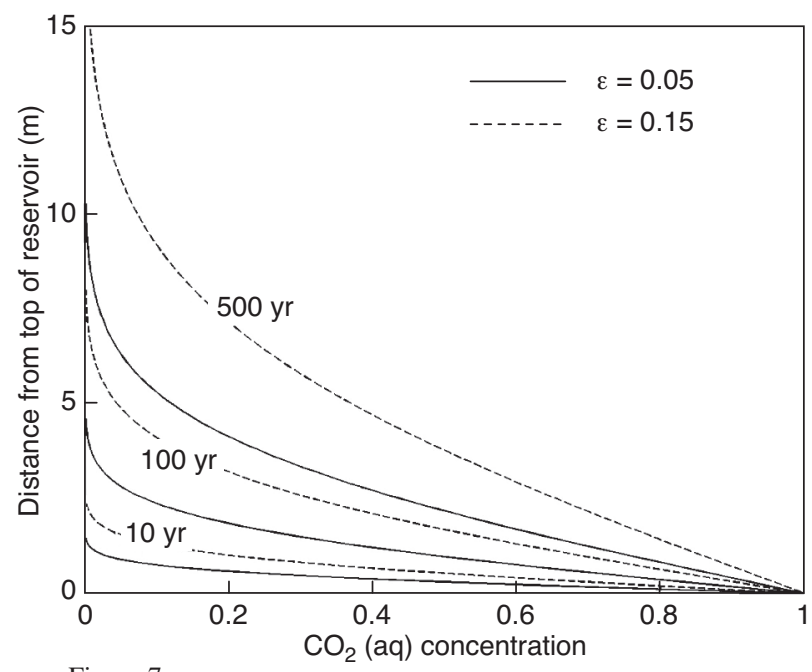

Figure 7

$\mathrm{CO}_{2}$ concentration profiles calculated for two porosity values (5 and 15\%) after 10, 100 and 500 year of diffusion at a temperature of $80^{\circ} \mathrm{C}$.

results (porosity close to $6 \%$, pore diffusion coefficient of the order of $2 \times 10^{-10} \mathrm{~m}^{2} / \mathrm{s}$, tortuosity about 10 ). The radioactive tracer technique was also applied to the other samples and indicated an effective diffusion coefficient in the $5 \times 10^{-12}$ $3 \times 10^{-11} \mathrm{~m}^{2} / \mathrm{s}$ range, with some variability between samples from the same core. Comparison with bicarbonate ions showed a significant decrease in the effective diffusion coefficient that could be attributed to anionic exclusion and marked interaction with the solid matrix. Lastly, simple rules for the extension of results to site conditions and possibly other types of rocks were proposed.

\section{ACKNOWLEDGEMENTS}

This work is part of the Géocarbone-Intégrité French program (2005-2008) supported by ANR. We thank P. Carles for choosing and providing the samples, F. Norrant for performing NMR experiments, E. Lasseur for the mineralogical analysis and C. Magnier for fruitful discussion.

\section{REFERENCES}

1 Busch A., Alles S., Gensterblum Y., Prinz D., Dewhurst D.N., Raven M.D., Stanjek H., Krooss B.M. (2008) Carbon dioxide storage potential of shales, Int. J. Greenhouse Gas Control 2, 297-308.

2 Shackelford C.D. (1991) Laboratory diffusion testing for waste disposal - A review, J. Contam. Hydrol. 7, 177-217.
3 Laguës M., Lesne A. (2003) Invariances d'échelle - Des changements d'état à la turbulence, Belin, Paris.

4 Quintard M., Bletzacker L., Chenu D., Whitaker S. (2006) Nonlinear multicomponent mass transport in porous media, Chem. Eng. Sci. 61, 8, 2643-2669.

5 Melkior T., Yahiaoui S., Motellier S., Thoby D., Tevissen E. (2005) Cesium sorption and diffusion in Bure mudrock samples, Appl. Clay Sci. 29, 3-4, 172-186.

6 Maes N., Salah S., Jacques D., Aertsens M., Van Gompel M., De Canniere P., Velitchkova N. (2008) Retention of Cs in Boom Clay: Comparison of data from batch sorption tests and diffusion experiments on intact clay cores, Phys. Chem. Earth Pt A/B/C 33, Suppl. 1, S149-S155.

7 Aertsens M., Van Gompel M., De Cannière P., Maes N., Dierckx A. (2008) Vertical distribution of the transport parameters in Boom Clay in the Mol-1 borehole (Mol, Belgium), Phys. Chem. Earth Pt A/B/C 33, Suppl. 1, S61-S66.

8 Carles P., Bachaud P., Lasseur E., Berne P., Bretonnier P., Confining properties of carbonaceous Dogger caprocks (Parisian Basin) for $\mathrm{CO}_{2}$ storage purpose, Oil Gas Sci. Technol. - Rev. IFP (submitted)

9 Guichet X., Fleury M., Kohler E. (2008) J. Colloid Interf. Sci. 327, 84.

10 Gosting L.J., Fujita H. (1957) J. Am. Chem. Soc. 79, 1359.

11 Crank J. (1975) The mathematics of diffusion, Oxford University Press, Oxford.

12 Appelo C.A.J., Postma B. (2005) Geochemistry, groundwater and pollution, 2nd ed., Balkema, Leiden.

13 Cormenzana J.L., Garcia-Guttierez M., Missana T., Alonso U. (2008) Modelling large-scale laboratory HTO and strontium diffusion experiments in Mont Terri and Bure clay rocks, Phys. Chem. Earth Pt A/B/C 33, 14-16, 949-956.

14 Holz M., Heiz S.R., Sacco A. (2000) Phys. Chem. Chem. Phys. 2, 4740 .

15 London South Bank University water structure and science web site, http://www.lsbu.ac.uk/water.

16 Pokrovsky O.S., Schott J., Thomas F. (1999) Processes at the magnesium-bearing carbonates/solution interface. I. A surface speciation model for magnesite, Geochim. Cosmochim. Ac. 63, 6, 863-880.

17 Madsen L. (2006) Calcite: surface charge, in Encyclopedia of Surface and Colloid Science, Vol. 8, pp. 1084-1096.

18 Eriksson R., Merta J., Rosenholm J.B. (2007) The calcite/water interface -1 . Surface charge in indifferent electrolyte media and the influence of low-molecular-weight polyelectrolyte, J. Colloid Interf. Sci. 313, 184-193.

19 Bachaud P., Berne Ph., Renard F., Sardin M., Leclerc J.P. (2009) Transport properties of very low permeability carbonate caprocks measured using radioactive tracers and transient pressure tests, Int. J. Greenhouse Gas Control (submitted).

20 Gonzalez Sanchez F., Van Loon L.R., Gimmi T., Jakob A., Glaus M.A., Diamond L.W. (2008) Self-diffusion of water and its dependence on temperature and ionic strength in highly compacted montmorillonite, illite and kaolinite, Appl. Geochem. 23, 3840-3851.

21 Hayduk W., Laudie H. (1974) AlChE 20, 611.

22 Ragland D.A. (2002) Petrophysics 43, 20.

Final manuscript received in August 2009 Published online in November 2009

\section{Copyright (C) 2009 Institut français du pétrole}

Permission to make digital or hard copies of part or all of this work for personal or classroom use is granted without fee provided that copies are not made or distributed for profit or commercial advantage and that copies bear this notice and the full citation on the first page. Copyrights for components of this work owned by others than IFP must be honored. Abstracting with credit is permitted. To copy otherwise, to republish, to post on servers, or to redistribute to lists, requires prior specific permission and/or a fee: Request permission from Documentation, Institut français du pétrole, fax. +33147527078 , or revueogst@ifp.fr. 